\title{
Factors in the marital relationship in a changing society
}

\author{
A Taiwan case study
}

\section{- April Chiung-Tao Shen}

The convergence of eastern Confucian and western individualistic ideologies in the 20th century in Taiwan had a significant impact on family structures and processes. Among the most dramatic changes was the increased occurrence of marital breakdowns. The divorce rate $(47 \%)$ in Taiwan is the highest of the Asian countries and has kept rising dramatically since the 1970s (ROC Ministry of Interior, 2005). The deleterious effects of marital distress on physical health, psychological well-being and workers' productivity are reliably documented (Fincham and Bradbury, 1987; Stanley et al., 1995). For traditional Chinese wives, discord and unhappiness are generally turned inward to the self and are reflected in a high suicide rate rather than in divorce statistics. Suicide has been the traditional form of protest for Chinese women who find life unbearable inside their matrimonial bonds (Ho, 1987). The high divorce rate and the adverse impact of marital distress continue to spur on the studies of marital stability and satisfaction (Fowers et al., 1996).

In addition, the components of marriage quality are unavoidably culture-bound, as the function of marriage varies across cultures (Adams, 1988). Although hundreds of studies have explored the quality of marriages, few studies have focused on Asian countries. The experience of some western societies shows that along with

April Chiung-Tao Shen is Assistant Professor in the Department of Social Work, National Taiwan University, 1 Roosevelt Rd, Sec. 4, Taipei, Taiwan, 106 ROC. [email: acshen@ntu.edu.tw] 
industrialization and urbanization, families move towards a conjugal model (Goode, 1963). Since Taiwan was transformed in the 20th century by industrialization, westernization, increased education and extended contacts with other cultures (Thornton and Lin, 1994), marital relationships seem also to be progressing toward the conjugal model or western style, which emphasizes affection and egalitarian relationship rather than the traditional Chinese roles and functions. Therefore, it is crucial to understand the nature of Taiwanese marriages at the beginning of the 21st century in order to understand how to enrich marriages and to prevent or alleviate marital distress.

One advantage of conducting marital research in Taiwan is that the population is relatively homogeneous. With the exception of a moderate number of aboriginal people, the population is mainly composed of Han Chinese who migrated to Taiwan from Mainland China in the 17th and 18th centuries. In addition, there has been little migration into or away from Taiwan during the past four decades. The early settlers of Han Chinese brought historical Chinese culture with them to Taiwan, so the family traditions of Taiwan were similar to those of Mainland China until the early 20th century (Thornton and Lin, 1994). For example, failure to marry and have children was viewed in Chinese culture as the most serious violation of filial piety because it threatened the continuation of the family line.

However, the convergence of traditional Chinese culture and modern western values in the 20th century in Taiwan had a significant effect on family structures and processes. The patterns of Taiwanese family life are gradually being redefined, with both direct and indirect effects on family life and marital relationships. Adjustments to these changes include the increased autonomy of young people, the shift from arranged marriages toward love matches, the postponement of marriage, the rise in divorce and the fall in fertility. In addition, the decline of extended families, the increased acceptance of remarriage, the equal relationship of husband and wife, and the weakening of intergenerational ties have been noted (Chien, 1996; Thornton and Lin, 1994). These significant adjustments have been balanced by an equally dramatic persistence of other aspects of family life: marriage continues to be nearly universal; parenthood is desired by nearly all; children receive extensive care from their parents; the elderly obtain support from their children and the ancestral chain remains a central, though 
weakened, value. It is expected that many of Taiwan's current family trends will persist (Thornton and Lin, 1994).

This study investigates the factors associated with marital satisfaction in a society in transition - Taiwan. The primary aim is to examine how cultural changes influence the social construction of a good or satisfying marriage as defined by the couples themselves.

\section{Method}

\section{Participants}

The participants in this study were 226 married couples (452 spouses) obtained from a proportionate stratified community sample in Taiwan. The sample was stratified by geographical location in eight major cities (two cities in the northern, two in the southern, two in the western and two in the eastern part of Taiwan) to increase representativeness in social class and in a broad range of attitudes. The data used in this paper were part of a larger study whose data were collected over a three-month period during the spring of 2001 in Taiwan (Shen, 2002).

The demographic characteristics of the participants were as follows (see Table 1). Approximately half of the couples were more than 40 years old and had been married for at least 16 years. The vast majority of the couples $(95.6 \%)$ had at least one child (median $=2$ ), and 4.4 percent of the sample did not have children. A large percentage $(69.0 \%)$ of the participants lived with their spouses and children (nuclear family), while 31 percent of the couples also lived with one of the spouse's parents or extended families (mostly the couple lived with the husband's parents, according to Chinese culture). Two-thirds $(64.7 \%)$ of the couples had married for love, and the rest of the sample were married because of family and age pressure, pregnancy and matchmaker arrangements.

In terms of education, 62.6 percent of the participants had at least finished high school. As for employment, participants were distributed fairly evenly among the public sector, private industry, the business sector and other occupations. More than one third of the female participants (37.2\%) were housewives. Although 14.6 percent stated no religious affiliations, 7.3 percent were Protestants or Catholics and 77 percent were Buddhists or Taoists.

\section{Measure}

This study employed an instrument called 'Multidimensional Marital Satisfaction Inventory' (MMSI) to assess the marital 
Table 1 Sample demographic characteristics $(N=226$ couples)

\begin{tabular}{|c|c|c|c|c|c|c|c|}
\hline \multirow[t]{2}{*}{ Characteristics } & & \multicolumn{2}{|c|}{ Total } & \multicolumn{2}{|c|}{ Males } & \multicolumn{2}{|c|}{ Females } \\
\hline & & $N$ & $\%$ & $N$ & $\%$ & $N$ & $\%$ \\
\hline \multirow[t]{6}{*}{ Years of marriage } & $0-3$ & 31 & 6.9 & 16 & 7.1 & 15 & 6.6 \\
\hline & $4-7$ & 69 & 15.3 & 34 & 15.0 & 35 & 15.5 \\
\hline & $8-11$ & 57 & 12.6 & 29 & 12.8 & 28 & 12.4 \\
\hline & $12-15$ & 73 & 16.2 & 37 & 16.4 & 36 & 15.9 \\
\hline & $16-19$ & 61 & 13.5 & 31 & 13.7 & 30 & 13.3 \\
\hline & 20 or more & 161 & 35.6 & 79 & 35.0 & 82 & 36.3 \\
\hline \multirow[t]{5}{*}{ Number of children } & 0 & 20 & 4.4 & 10 & 4.4 & 10 & 4.4 \\
\hline & 1 & 60 & 13.3 & 30 & 13.3 & 30 & 13.3 \\
\hline & 2 & 176 & 38.9 & 88 & 38.9 & 88 & 38.9 \\
\hline & 3 & 166 & 36.7 & 83 & 36.7 & 83 & 36.7 \\
\hline & 4 or more & 30 & 6.6 & 15 & 6.6 & 15 & 6.6 \\
\hline \multirow[t]{4}{*}{ Education } & Finished middle school & 108 & 23.9 & 44 & 19.5 & 64 & 28.3 \\
\hline & Finished high school & 175 & 38.7 & 84 & 37.2 & 91 & 40.3 \\
\hline & $\begin{array}{l}\text { Two-year college or } \\
\text { university }\end{array}$ & 146 & 32.3 & 79 & 35.0 & 67 & 29.6 \\
\hline & Graduate school & 23 & 5.1 & 19 & 8.4 & 4 & 1.8 \\
\hline
\end{tabular}




\begin{tabular}{|c|c|c|c|c|c|c|c|}
\hline \multirow[t]{5}{*}{ Age } & $20-24$ & 5 & 1.1 & 1 & 0.4 & 4 & 1.8 \\
\hline & $25-29$ & 23 & 5.1 & 7 & 3.1 & 16 & 7.1 \\
\hline & $30-34$ & 68 & 15.0 & 28 & 12.4 & 40 & 17.7 \\
\hline & $35-39$ & 83 & 18.4 & 40 & 17.7 & 43 & 19.0 \\
\hline & 40 or above & 273 & 60.4 & 150 & 66.4 & 123 & 54.4 \\
\hline \multirow[t]{4}{*}{ Religious affiliation } & Buddhist/Taoist & 347 & 76.9 & 175 & 77.4 & 172 & 76.4 \\
\hline & Catholic/Protestant & 33 & 7.3 & 17 & 7.5 & 16 & 7.1 \\
\hline & None & 66 & 14.6 & 31 & 13.7 & 35 & 15.6 \\
\hline & Others & 5 & 1.1 & 3 & 1.3 & 2 & 0.9 \\
\hline \multirow[t]{10}{*}{ Occupation } & $\begin{array}{l}\text { Soldier/civil servant/ } \\
\text { teacher }\end{array}$ & 70 & 15.5 & 39 & 17.3 & 31 & 13.7 \\
\hline & Industry, business & 87 & 19.2 & 58 & 25.7 & 29 & 12.8 \\
\hline & Laborer & 68 & 15.0 & 51 & 22.6 & 17 & 7.5 \\
\hline & Services & 71 & 15.7 & 33 & 14.6 & 38 & 16.8 \\
\hline & Self-employed & 39 & 8.6 & 23 & 10.2 & 16 & 7.1 \\
\hline & Information technology & 7 & 1.5 & 4 & 1.8 & 3 & 1.3 \\
\hline & Housewife & 84 & 18.6 & 0 & 0 & 84 & 37.2 \\
\hline & Unemployed & 17 & 3.8 & 10 & 4.4 & 7 & 3.1 \\
\hline & Other/student & 9 & 2.0 & 8 & 3.5 & 1 & 0.4 \\
\hline & & & & & & \multicolumn{2}{|c|}{ continued on next page } \\
\hline
\end{tabular}


Table 1 (continued)

\begin{tabular}{|c|c|c|c|c|c|c|c|}
\hline \multirow[t]{2}{*}{ Characteristics } & & \multicolumn{2}{|c|}{ Total } & \multicolumn{2}{|c|}{ Males } & \multicolumn{2}{|c|}{ Females } \\
\hline & & $N$ & $\%$ & $N$ & $\%$ & $N$ & $\%$ \\
\hline \multirow{7}{*}{$\begin{array}{l}\text { Individual monthly } \\
\text { income, New } \\
\text { Taiwan } \$ \\
\text { (NT\$: US\$ = 34:1) }\end{array}$} & 0 & 86 & 19.2 & 9 & 4.0 & 77 & 34.4 \\
\hline & $1-19,999$ & 49 & 11.0 & 18 & 8.1 & 31 & 13.8 \\
\hline & $20,000-39,999$ & 127 & 28.4 & 64 & 28.7 & 63 & 28.1 \\
\hline & $40,000-59,999$ & 80 & 17.9 & 52 & 23.3 & 28 & 12.5 \\
\hline & $60,000-79,999$ & 55 & 12.3 & 38 & 17.0 & 17 & 7.6 \\
\hline & $80,000-99,999$ & 17 & 3.8 & 14 & 6.3 & 3 & 1.3 \\
\hline & 100,000 or more & 33 & 7.4 & 28 & 12.6 & 5 & 2.2 \\
\hline \multirow[t]{4}{*}{ Living arrangement } & $\begin{array}{l}\text { With spouse \& extended } \\
\text { family }\end{array}$ & 50 & 11.1 & 25 & 11.1 & 25 & 11.1 \\
\hline & With spouse \& parents & 90 & 19.9 & 45 & 19.9 & 45 & 19.9 \\
\hline & With spouse \& kids & 302 & 66.8 & 151 & 66.8 & 151 & 66.8 \\
\hline & With spouse only & 10 & 2.2 & 5 & 2.2 & 5 & 2.2 \\
\hline \multirow{2}{*}{ Family life cycle } & Couple with no child & 30 & 6.8 & 15 & 6.8 & 15 & 6.8 \\
\hline & Preschool child & 142 & 32.1 & 71 & 32.1 & 71 & 32.1 \\
\hline
\end{tabular}




\begin{tabular}{|c|c|c|c|c|c|c|c|}
\hline & School-age child & 84 & 19.0 & 42 & 19.0 & 42 & 19.0 \\
\hline & Teenage child & 102 & 23.1 & 51 & 23.1 & 51 & 23.1 \\
\hline & $\begin{array}{l}\text { Children living away } \\
\text { from home }\end{array}$ & 84 & 19.0 & 42 & 19.0 & 42 & 19.0 \\
\hline \multirow[t]{4}{*}{ Employment } & Full-time & 303 & 67.2 & 191 & 84.5 & 112 & 49.6 \\
\hline & Part-time & 36 & 8.0 & 9 & 4.0 & 27 & 11.9 \\
\hline & Full-time \& part-time & 20 & 4.4 & 11 & 4.9 & 9 & 4.0 \\
\hline & Unemployed & 92 & 20.4 & 14 & 6.2 & 78 & 34.5 \\
\hline \multirow[t]{6}{*}{ Reasons for marriage } & Married for love & 290 & 64.7 & 144 & 64.0 & 146 & 65.5 \\
\hline & $\begin{array}{l}\text { Matchmaker } \\
\text { arrangement }\end{array}$ & 73 & 16.3 & 39 & 17.3 & 34 & 15.2 \\
\hline & Family pressure & 5 & 1.1 & 2 & 0.9 & 3 & 1.3 \\
\hline & Age pressure & 61 & 13.6 & 31 & 13.8 & 30 & 13.5 \\
\hline & Pregnant & 15 & 3.3 & 9 & 4.0 & 6 & 2.7 \\
\hline & Others & 4 & 0.9 & 0 & 0 & 4 & 1.8 \\
\hline
\end{tabular}

Notes

Categories may not sum up to 452 due to missing data. However, percentages do sum to $100 \%$. Each couple answered the inventory separately and independently, so that some couples answered differently in terms of years of their marriage. 
relationships of Taiwanese couples. The MMSI is a 58 -item multidimensional marital satisfaction inventory developed in 2001 by the author. The MMSI contains 12 scales. These are as follows.

- Personality issues

- Couple closeness

- Couple flexibility

- Financial management

- Leisure activities

- Sexual relationship

- Children and parenting

- Family and friends

- Gender role

- Values

- Social desirability

- Marriage satisfaction

Each scale consists of five items except Social desirability and Marriage satisfaction, each of which comprises only four items.

Statistical analyses showed that the MMSI has high levels of reliability and validity. The internal consistency (alpha) of the total MMSI was .96. The median internal consistency (alpha) across scales of the MMSI was .79, ranging from a low of .62 (Gender role) to a high of .83 (Couple closeness). In terms of discriminant validity, all the MMSI scales were able to discriminate the most satisfied couples from the least satisfied couples. In sum, the alpha reliability tests and the discriminant analyses procedures indicated that the MMSI has high levels of internal consistency reliability and discriminant validity. The result suggests that this instrument provides internally consistent indexes of marital relations in the Taiwanese population (Shen, 2002).

\section{Results}

In terms of responses to the one-item marital satisfaction question ('How satisfied are you with your marriage?'), the majority (85\%) of the Taiwanese reported satisfaction with their marriage. This result was consistent with that of previous Taiwanese studies (Chu, 1991; ROC Executive Yuan, 1998; Shen, 1999, 2002). Despite the dramatic increase in divorce rate over the years, the percentage of reported marital satisfaction (approximately $85 \%$ ) is surprisingly stable regardless of whether a 5-point, 7-point or 10-point Likert 
scale is used. These results might suggest that Taiwanese tend to describe their marriage in an over-positive manner, which might be due to the strong social desirability of marital harmony in Taiwanese society (Shen, 1999). The fear of losing face might also be a powerful motivating force for conforming to social expectations of marital harmony.

A multiple regression analysis was conducted to examine the relative importance of factors (MMSI scale scores) as predictors of marital satisfaction. Separate analyses were conducted for couples over 40 years old and for couples under 40 years old, in order to examine the impact of the generation factor on predicting marital satisfaction. The criterion measure (dependent variable) was the couple scores on the Marriage satisfaction sub-scale. This study added together the husband's scores and the wife's scores on the Marriage satisfaction sub-scale in order to examine the dyadic relationship between Taiwanese spouses. Ten MMSI scales were entered by stepwise method as potential predictors (independent variables), including Personality issues, Couple closeness, Couple flexibility, Financial management, Leisure activities, Sexual relationship, Children and parenting, Family and friends, Gender role and Values.

Table 2 presents the multiple regression models following stepwise entry of the MMSI scale couple scores for predicting the scores of the Marriage satisfaction sub-scale. The multiple correlation of the MMSI scale variables with couple satisfaction was $.85\left(\mathrm{R}^{2}=.72\right.$, $p<.000$ ), showing that Model 1 was significant. According to this procedure, Marital satisfaction scale scores were predicted significantly by Couple closeness, Personality issues, Family and friends, and Sexual relationship. Other scales were not significant at the 0.05 level.

Separate multiple regression analyses were also conducted for the couples who were over and under 40 years old to examine whether there were generational differences in terms of what scales were the significant predictors for older couples and for younger couples. The dependent and independent variables were the same as those of Model 1 presented in Table 2. Model 2 (older couples) and Model 3 (younger couples) exhibited results very similar to Model 1 (total couples). Compared with those for the total couples, the significant predictors of marital satisfaction and their relative importance (see Beta in Table 2) for the older couples were exactly the same, except for Gender role. For younger couples, the first three significant predictors of marital satisfaction were also the same, except 
Table 2 Significant predictors of marital satisfaction based on multiple regression

\begin{tabular}{|c|c|c|c|c|c|c|c|}
\hline Model & $\begin{array}{l}\text { Dependent } \\
\text { variable }\end{array}$ & $\mathbf{R}$ & $\mathbf{R}^{2}$ & $\mathbf{F}$ & $\begin{array}{l}\text { Significant independent } \\
\text { variables }\end{array}$ & Beta & $\mathbf{T}$ \\
\hline $\begin{array}{l}\text { Model 1: } \\
N=226 \text { couples }\end{array}$ & $\begin{array}{l}\text { Marriage } \\
\text { satisfaction sub- } \\
\text { scale }\end{array}$ & .85 & .72 & $122.4 * * *$ & $\begin{array}{l}\text { Couple closeness } \\
\text { Personality issues } \\
\text { Families \& friends } \\
\text { Sexual relationship }\end{array}$ & $\begin{array}{l}.38 \\
.28 \\
.21 \\
.16\end{array}$ & $\begin{array}{l}6.5^{* * *} \\
5.5^{* * *} \\
4.1^{* * *} \\
3.2^{* *}\end{array}$ \\
\hline $\begin{array}{l}\text { Model } 2 \text { : } \\
N=121 \text { couples } \\
\text { over } 40 \text { years old }\end{array}$ & $\begin{array}{l}\text { Marriage } \\
\text { satisfaction sub- } \\
\text { scale }\end{array}$ & .85 & .72 & $54.4 * * *$ & $\begin{array}{l}\text { Couple closeness } \\
\text { Personality issues } \\
\text { Families \& friends } \\
\text { Sexual relationship } \\
\text { Gender role }\end{array}$ & $\begin{array}{l}.31 \\
.26 \\
.23 \\
.15 \\
.13\end{array}$ & $\begin{array}{l}3.7^{* * * *} \\
3.6^{* * * *} \\
3.0^{* *} \\
2.2^{*} \\
2.1^{*}\end{array}$ \\
\hline $\begin{array}{l}\text { Model 3: } \\
N=105 \text { couples } \\
\quad \text { under } 40 \text { years old }\end{array}$ & $\begin{array}{l}\text { Marriage } \\
\text { satisfaction sub- } \\
\text { scale }\end{array}$ & .86 & .73 & $57.5^{* * *}$ & $\begin{array}{l}\text { Couple closeness } \\
\text { Personality issues } \\
\text { Families \& friends } \\
\text { Financial management }\end{array}$ & $\begin{array}{l}.42 \\
.24 \\
.21 \\
.17\end{array}$ & $\begin{array}{l}5.2^{* * * *} \\
3.3^{* * *} \\
2.8^{* *} \\
2.4^{*}\end{array}$ \\
\hline
\end{tabular}

$* p<.05 ; * * p<.01 ; * * * p<.001$ 
that the fourth significant predictor was Financial management, instead of Sexual relationship. Comparing the three regression models, we can conclude that Couple closeness, Personality issues, and Families and friends were the most important or significant factors associated with marital satisfaction, no matter what generation the couples were. It appears that modernization has a similar impact on the marital relationship for all the different age groups of the sample.

\section{Discussion}

Francis Hsu (1988) (cited in Peng, 2003) compared the family systems of Chinese society with those of American society. He pointed out that the father-son relationship is the dominant dyad in Chinese society, and the couple relationship is the dominant dyad in American families. There are three characteristics associated with the Chinese culture dominated by the father-son relationship: continuation of the family line, obeying parental authority and devaluing the importance of sex and intimacy in family relationships.

However, as industrialization and modernization proceed, families in Taiwan seem to have increasingly adopted a conjugal model of relationships, emphasizing love and affection between couples, rather than the father-son relationship of traditional Chinese culture. The conjugal model emphasizes the centrality of the spousal relationship. A conjugal unit is represented by a nuclear family, with the couple and their children living in a separate household. Affection and care-giving are shared, and loyalty is focused on the nuclear unit, which maintains contacts and exchanges mutual assistance with the extended families (Young, 1995). This explanation is supported by the findings that Couple closeness, Personality issues, Family and friends, and Sexual relationship were positively associated with marital satisfaction. Couple closeness, Personality issues and Sexual relationship were all factors that reveal the importance of the interpersonal relationship between couples. Family and friends was the only factor that reflected the effect of outside influences on the marital subsystem. This section discusses the findings on the factors associated with marital satisfaction in the context of cultural changes in Taiwan.

\section{Couple closeness}

This describes the level of emotional closeness experienced between couples. The items deal with couples trusting, caring and supporting 
each other, willing to stay with each other for ever, and being able to share feelings and ideas with each other. This study found that closeness between couples was the most important factor that was positively related to marital satisfaction. This result is consistent with Lewinsohn and Werner's (1997) finding that couple closeness has a positive linear relationship with marital quality. This result is inconsistent with Ying's (1991) conclusions that Chinese marital quality is not related to the quality of emotional interactions within the marriage. Traditional Chinese culture devalues the importance of sex and intimacy in the family relationship. The present result may reflect the impact of cultural change and modernization on marital relationship in Taiwan, in which emotional closeness has become fundamental to satisfying marriages.

\section{Personality issues}

This assesses each individual's perception and satisfaction with the personality characteristics of their partner as expressed through their attitudes and behavioral traits. The items focus on issues such as whether the spouse is stubborn or not, easy to get along with or not and the way the spouse handles things. Traditionally, the definition of a good match and successful marriage in Chinese culture was not necessarily based upon compatibility and romantic interest between the spouses. However, as the role of parents in mate selection is sharply declining, the selection of mates by young people is becoming more prevalent in Taiwan (Thornton and Lin, 1994). With the declining role of the parents and the increasing focus on the wishes of the individual, traditionally collectivist societies are undergoing an explicit process of individualization at the very heart of the institution of marriage. Such change erodes the moral basis for marriage as a lifelong contract. If the purpose of marriage is to enjoy the companionship of a compatible partner, then having a partner that one does not find compatible can justifiably be interpreted as grounds for ending the marriage (Mason et al., 1998). Since most Taiwanese get married for love nowadays, they may have higher expectations for personality compatibility between spouses, and hence, lower tolerance toward their spouses once they think their spouse has changed. In fact, personality incompatibility is the most frequently cited reason (or excuse) for divorce in Taiwan. Declining commitment involves potentially bad effects on children who may thus be reared in an unstable family. 


\section{Family and friends}

This assesses feelings and concerns about relationships with relatives, in-laws and friends. The items focus on the interference of family and friends in the marriage, and the perceptions of family and friends as conflict or satisfaction. Couples in Taiwan may have great pressure from family members, especially from in-laws. Traditionally, Chinese marriage has been viewed as the continuation of the husband's family line through the birth of a male child, rather than as the beginning of a new and separate family (Ho, 1987). In traditionally patriarchal family structures, eldest sons were dutybound to live with and care for their aging parents. Nevertheless, it was the eldest son's wife who physically cared for her aging parents-in-law, not the son himself. However, the trends of rapidly advancing women's educational attainment have changed the dynamics of marital and family relationships (Mason et al., 1998). For example, the traditional mother-in-law is usually less educated, and hence has fewer resources than her modernized daughter-in-law. This may uproot the traditional power structure between mother-inlaw and daughter-in-law, in which the daughter-in-law has the least power in an extended family and is supposed to obey her mother-inlaw. Moreover, well-educated couples are less likely to begin married life with parents or they terminate such extended household arrangements more rapidly (Freedman et al., 1994). This may upset the parents who wish to live with their sons. In addition, because of the rapid increase in employment of married women outside the home, mothers-in-law often help care for their grandchildren. Conflicts arise when two generations have different ways of raising children (Chien, 1996). Therefore, the involvement of extended family members (e.g. parents) can be a source of support or resources, but also a source of conflict or problems, especially when different generations have different expectations of family life or structure. This may indicate that although Taiwanese marriages are progressing from a traditional one to a conjugal one, family members, especially in-laws, still have great influence over the marital relationship, which constitutes an important factor that differentiates between satisfactory and unsatisfactory marriages.

\section{Sexual relationship}

This item assesses an individual's feelings and concerns about affection and the sexual relationship with his/her partner. The items mainly reflect satisfaction with the sexual relationship and the level of comfort in discussing sexual issues. The result is consistent 
with Lewinsohn and Werner's finding that physically intimacy is a factor positively correlated with the marital relationship. Although traditional Chinese culture devalues the importance of sex in the family relationship, the present result shows that sexual satisfaction has gained importance in marital relations.

\section{Financial management}

For the younger generation in Taiwan, financial management emerged as a significant factor associated with marital satisfaction. Financial management focuses on attitudes and concerns about the way economic issues are managed and the couple's satisfaction with their economic status. Younger couples in Taiwan seem to have greater concerns over economic issues, since they need to establish economic security on their own, rather than depending on their parents.

\section{Gender role}

This evaluates an individual's beliefs, attitudes and feelings about marital and family roles, and the division of labor. Low scores suggest that the individual's values tend to be egalitarian in nature. High scores indicate that the individual values more traditional male/female role behaviors and responsibilities. Since the result found that gender role was positively associated with marital satisfaction among the older generation, it indicates that the older generation values more traditional gender roles than the younger generation.

In terms of implications for marital practice, research suggests that the physical and psychological well-being of adults may be enhanced by social interventions that promote the quality of their intimate relationships (Bowen and Kilpatrick, 1995). The findings on the predictors of marital satisfaction can better structure the education and enrichment program to prevent marital discord and to help couples learn the interpersonal skills needed to make their relationships more satisfying and fulfilling.

\section{Conclusion}

This study contributes to marital research by examining factors associated with marital satisfaction in a society progressing from a traditional culture to a modern one. The results suggest that marriages in Taiwan are responding to modernizing forces by undermining the traditional values and practices based on the gender and 
age differentials of the patriarchal family, and are becoming more like families in the west. Nevertheless, intergenerational relationships remain distinct, indicating that Taiwanese marriages are still progressing from an institutional marriage to a conjugal marriage. Therefore, the convergence of eastern and western family values in Taiwan has produced unique responses to modernization, in which the spousal relationship has become the primary dyad in marriage, and where the intergenerational relationship is a subsidiary to modern Taiwanese society.

\section{Acknowledgement}

This study was funded by the National Science Council, Taiwan (Grant No.: NSC-89-2412-H-260-012).

\section{References}

Adams, B.N. (1988) 'Fifty Years of Family Research: What Does It Mean?', Journal of Marriage and the Family 50: 5-17.

Bowen, G.L. and A.C. Kilpatrick (1995) 'Marriage/partners', 19th Encyclopedia of Social Work. Washington, DC: National Association of Social Workers.

Chien, C.A. (1996) Marriage and the Family. Taipei, Taiwan: National Open University Press (in Chinese).

Chu, C.L. (1991) Marital Research. Taipei, Taiwan: Grand East Book Company (in Chinese).

Fincham, F.D. and T.N. Bradbury (1987) 'The Assessment of Marital Quality: A Reevaluation', Journal of Marriage and the Family 49: 797-809.

Fowers, B.J., K.H. Montel and D.H. Olson (1996) 'Predicting Marital Success for Premarital Couple Types Based on PREPARE', Journal of Marital and Family Therapy 22(1): 103-19.

Freedman, D.S., A. Thornton and L.S. Yang (1994) 'Determinants of Co-Residence in Extended Households', in A. Thornton and H.S. Lin (eds) Social Change and the Family in Taiwan, pp. 335-58. Chicago, IL: University of Chicago Press.

Goode, W.J. (1963) World Revolution and Family Patterns. New York: Free Press.

Ho, M.K. (1987) Family Therapy with Ethnic Minorities. Newbury Park, CA: Sage.

Lewinsohn, M.A. and P.D. Werner (1997) 'Factors in Chinese Marital Process: Relationship to Marital Adjustment', Family Process 36(1): 43-61.

Mason, K.O., N.O. Tsuya and M.K. Choe (1998) The Changing Family in Comparative Perspective: Asia and the United States. Honolulu, HI: East-West Center.

Peng, H.C. (2003) Marriage and the Family, 3rd edn. Taipei, Taiwan: Chu Liu Book Company (in Chinese).

Republic of China (ROC) Executive Yuan (1998) Social Development Trends Survey Report in Taiwan. General Budget, Accounting and Statistics, Executive Yuan, Republic of China.

Republic of China (ROC) Ministry of the Interior (2005) http://www.moi.gov.tw/stat/ index.asp 
Shen, April Chiung-Tao (1999) 'Predictors of Marital Satisfaction in Taiwan'. Unpublished PhD dissertation. Minneapolis, MN: University of Minnesota.

Shen, April Chiung-Tao (2002) 'Developing a Multi-Dimensional Marital Satisfaction Inventory for Taiwanese Couples', Formosa Journal of Mental Health 15(3): 67-100 (in Chinese).

Stanley, S.M., H.J. Markman, M. St Peters and B.D. Leber (1995) 'Strengthening Marriages and Preventing Divorce: New Directions in Prevention Research', Family Relations 44: 392-401.

Thornton, A. and H.S. Lin, eds (1994) Social Change and the Family in Taiwan. Chicago, IL: University of Chicago Press.

Ying, Y.W. (1991) 'Marital Satisfaction among San Francisco Chinese-Americans', International Journal of Social Psychiatry 37(3): 201-13.

Young, K.P.H. (1995) Understanding Marriage: A Hong Kong Case Study. Hong Kong: Hong Kong University Press. 